\title{
Segurança Energética e Mudanças Climáticas na União Europela*
}

Giorgio Romano**

\section{Introdução}

No século XXI, a discussão em torno da mudança climática alterou o olhar sobre a política energética no âmbito global. O ponto de partida é que a emissão de gases de efeito estufa (GEE), em particular dióxido de carbono, metano e óxido nitroso, provoca aquecimento global com consequências para a instabilidade climática, provocando um aumento estatístico dos desastres naturais com grandes impactos, inclusive para a produção alimentar. E a emissão de GEE, na

\footnotetext{
* Artigo recebido em 13 de agosto de 2013 e aprovado para publicação em $1^{\circ}$ de abril de 2014. Este artigo é baseado em um estudo realizado em Bruxelas, em setembro de 2012, que envolveu entrevistas com cerca de vinte stakeholders.

** Doutor em Sociologia pela Universidade de São Paulo (USP), professor adjunto III da Universidade Federal do ABC (UFABC), coordenador do curso de Relações Internacionais e membro do corpo docente do Programa de Pós-graduação em Ciências Humanas e Sociais e do Bacharelado em Ciências Econômicas da UFABC. E-mail: giorgio.romano.schutte@ gmail.com.
} 
maioria das vezes, resulta da queima de combustíveis fósseis (carvão, petróleo e gás). Há basicamente três caminhos alternativos para enfrentar esse problema. O primeiro é a substituição de energias fósseis por energias renováveis ou com menor emissão de GEE (a troca de carvão e petróleo pelo gás, por exemplo). O segundo é a alteração da estrutura de demanda, em particular a partir de um esforço significativo no âmbito da eficiência energética. E o terceiro é o desenvolvimento de uma tecnologia, ainda inexistente, de captura e sequestro de carbono (CSC). No caso da União Europeia (UE), há um problema adicional e anterior, que, em tese, poderia coincidir com a luta contra o aquecimento global: a preocupação com a segurança energética.

A preocupação com a segurança energética entrou na pauta da UE com o choque de petróleo de 1973 e se referiu à segurança de abastecimento de petróleo e gás. Não se trata de uma redução absoluta da dependência externa, mas de minimizar os riscos dessa dependência, alta e crescente no caso da União Europeia (SILVA, 2007).

Mais tarde, a UE definiu esse conceito como:

A segurança do abastecimento no campo da energia significa assegurar, para o bem público e para o funcionamento eficaz da economia, a disponibilidade física ininterrupta de energia no mercado a preços competitivos para todos os consumidores (privados e industriais), no quadro do objetivo de um desenvolvimento sustentável previsto no Tratado de Amsterdã (EUROPEAN COMMISSION, 2001, p. 10).

E no documento de política para a segurança europeia o tema aparece de forma explícita:

A dependência energética é uma preocupação especial para a Europa, que é o maior importador de petróleo e gás. Suas importações corres- 
Segurança Energética e Mudanças Climáticas na União Europeia

pondem atualmente a $50 \%$ do consumo de energia e devem aumentar para 70\% em 2030. A maioria das importações vem das regiões do Golfo Árabe, da Rússia e África do Norte (EUROPEAN UNION, 2003, p. 3).

Ou seja, independentemente da questão climática e dos GEE, a UE teria a preocupação de diminuir sua dependência de energia fóssil, uma vez que esta se torna cada vez mais escassa naquele território, o que justificaria investimentos e política para a promoção de eficiência energética e o uso de energias renováveis. De outro lado, a segurança de suprimento e a promoção da sustentabilidade ambiental, em particular o combate à mudança climática, devem dialogar com a competitividade da economia europeia em relação a outras regiões. E a estrutura de custo da energia é um fator de grande relevância também na concorrência pelos mercados.

Nas negociações internacionais, a Comunidade Europeia era vista como o ator mais ambicioso desde a Conferência Rio 1992 e assim se projetou (ADELLE et al., 2012, p. 25). A meta regional de concentrar esforços para limitar o aquecimento global a $2^{\circ} \mathrm{C}$ com relação aos patamares pré-industriais, por exemplo, tornou-se uma referência mundial no debate.

Na seção 1 deste trabalho, será analisada a trajetória da política energética comunitária, identificando quatro fases, sendo que o ativismo da Comissão Europeia se demonstra no início da década de 2000, em particular a partir de 2005, desdobrando-se em um conjunto de normas ambiciosas e inovadoras com o Pacote Energia-Clima (2008). Na seção 2, serão avaliados os resultados, apontando que houve, de fato, avanços significativos que devem ser atribuídos a um conjunto de legislação mandatória com metas objetivas e mecanismos de monitoramento. Não obstante isso, a mesma seção trata também dos limites dessa estratégia e da continuidade da dependência de importação de energia. Na seção 3, será analisada a política energética inter- 
nacional da UE, em particular em relação ao seu principal fornecedor, a Rússia. O impacto da crise global é objeto da seção 4, que demonstra o risco de retrocesso no contexto das dificuldades gerais vivenciadas pelo processo de integração europeia. A partir do final de 2008, a crise econômica mudou o cenário econômico, político e social. Ela chegou logo depois de um período de avanços importantes na legislação europeia, relacionado à energia e às mudanças climáticas. Se, de um lado, a crise gerou outras preocupações e pressionou a capacidade financeira do poder público das empresas e dos consumidores, de outro ela fomentou a defesa de políticas de estímulo a investimentos em eficiência energética para baixar os custos dos consumidores, reduzir o déficit na conta externa de energia e gerar emprego e tecnologia. A crise gerou também a falsa impressão de que se havia avançado na redução da emissão de GEE em virtude da redução da atividade econômica.

O debate em torno dos avanços e retrocessos da UE tem relevância também para as discussões em outras regiões, exatamente devido ao suposto papel de liderança que ela exercia. Quando a UE estabelece, por exemplo, normas rígidas e mandatórias para os países-membros, há um impacto sobre os produtores globais para se adaptarem a esses padrões em suas operações globais, ou, de qualquer forma, essas normas começam a servir como parâmetros. Esse é o caso do padrão de qualidade do diesel Euro-5, adotado em 2013 também pelo Brasil.

O trabalho é baseado em uma análise de vasta documentação oficial da Comissão, uma revisão da literatura recente a respeito desse assunto, ambas submetidas a um processo de diálogo com um conjunto de atores relevantes atuando em Bruxelas, dentro e fora da estrutura da Comissão e do Parlamento Europeu. Foram realizadas vinte entrevistas qualitativas focadas em entender melhor os avanços, obstáculos e perspectivas, diante do impacto da crise, da política de clima e de energia da UE. ${ }^{1}$ 
Segurança Energética e Mudanças Climáticas

na União Europeia

\section{Trajetória da Política Energética Comunitária}

A trajetória da política energética da UE pode ser subdividida em quatro fases. Na primeira fase, nos primórdios do processo de integração, houve as articulações em torno do carvão e da energia nuclear, mas o tema acabou à margem da agenda política comunitária. A segunda fase surgiu no início da década de 1990, no contexto dos preparativos e dos desdobramentos da Conferência Rio 1992, quando a Comunidade Europeia começou a projetar-se internacionalmente na área ambiental e a Comissão, órgão executivo de caráter supranacional, lançou propostas que dizem respeito à área energética, mas ainda sem encontrar respaldo no Conselho, órgão interministerial. Na terceira fase, no início da década de 2000, a Comissão começou a demonstrar grande ativismo, com apoio da Parlamento Europeu e do Conselho, o que resultou na implementação de um conjunto de legislações (principalmente diretivas) ${ }^{2}$ que se caracterizaram, em um primeiro momento, por serem voluntárias. Mas logo, diante dos avanços insatisfatórios, a Comissão optou por um ativismo ainda maior, e elaborou um conjunto de diretivas com normas vinculantes e até, em alguns casos, regulamentos, que se articulam em torno do Pacote Energia-Clima, lançado em 2008. Essa política da Comissão ganhou uma nova dimensão, com a introdução do tema no Tratado de Lisboa, que entrou em vigor em 2009. Observamos, portanto, que quando explodiu a crise com a quebra do Lehman Brothers nos Estados Unidos, em setembro de 2008, a UE estava em um ritmo intenso para revolucionar sua estrutura de demanda e oferta na área de energia, com efeitos significativos sobre as emissões de GEE. A quarta fase coincide com o impacto prolongado da crise econômico-financeira, o que colocou os avanços alcançados sob pressão, dificultando a sua consolidação. 


\section{$1.1 \mathrm{Um}$ passo à frente}

Foi em outubro de 1990 que o Conselho discutiu pela primeira vez metas para estabilizar as emissões de $\mathrm{CO}_{2}$. $\mathrm{O}$ tema entrou no Tratado de Maastricht (1992):

As exigências em matéria de proteção do ambiente devem ser integradas na definição e execução das políticas e ações da União, em especial com o objetivo de promover um desenvolvimento sustentável. ${ }^{3}$

Em seguida, a Comissão propôs um pacote ousado sobre energia renovável e eficiência energética, mas não encontrou apoio no Conselho (SANDOVAL; MORATA, 2012, p. 7). A discussão não estava madura ainda. De qualquer forma, marcou o início da entrada do tema na agenda europeia. Toda a discussão na década de 1990 enfocou a aproximação do tema da energia à questão ambiental. A assinatura do Protocolo de Kyoto, em 1997, embora tenha entrado em vigor somente em 2005, foi outro marco que estimulou a adoção de medidas concretas. Surgiu a noção de "europeização da governança energética" (SANDOVAL; MORATA, 2012, p. 8). Isso se refere ao surgimento cada vez mais forte de uma variável independente que impacta a política doméstica com poder transformador e o processo de adaptação da dinâmica nacional.

A principal proposta da Comissão no início da década de 1990 era o imposto sobre o carbono (carbon tax) (ADELLE et al., 2012, p. 40). Em seguida, a Comissão optou por apoiar o modelo de certificação, inclusive com direito a comercialização. E, assim, a comercialização dos certificados de emissões (em inglês, Emissions Trading Scheme (ETS)) tornou-se o principal instrumento para provocar uma redução das emissões na UE. O ETS foi apresentado pela Comissão em outubro de 2001 e aprovado pelo Conselho em 2003 (Diretiva 2003/87/EC). Por força dessa legislação, cada emissor industrial deve obter uma autorização para gerar cada tonelada de GEE. O es- 
quema aplica-se somente a produtores de energia e indústrias intensivas em energia. As licenças são comercializadas a preços de mercado, por isso as companhias têm interesse em reduzir suas emissões, para ter de comprar menos ou para vender um excedente. Para criar esse mercado, a UE colocou, em um primeiro momento, certificados de direito à emissão à disposição da indústria. Parte da receita fiscal obtida com a venda dos certificados era canalizada para subsidiar novas fontes de energia. A penalidade pelo não cumprimento das normas foi estabelecida em 40 euros por tonelada de GEE emitido sem certificado. Uma revisão dessa diretiva foi feita no âmbito do Pacote Energia-Clima em 2008 (ver em seguida) para corrigir algumas falhas e dar maior governabilidade para a Comissão.

\subsection{Dois passos adiante}

A opção pela construção de uma política abrangente na área de energia foi feita em outubro de 2005, na Cúpula do Conselho em Hampton Court, onde estavam em discussão dois assuntos: as mudanças climáticas e o aumento constante do preço de petróleo, que tinha atingido, naquele momento, 70 dólares por barril (EUROPEAN COMMISSION, 2010b). A pedido do Conselho, a Comissão iniciou a elaboração daquilo que era chamado de "estratégia europeia para a sustentabilidade, competitividade e segurança energética". A partir daí, a Comissão assumiu um ativismo que encontrou respaldo no Conselho, formulando, em janeiro de 2007, seu primeiro Plano de ação: uma política energética para Europa; e, em janeiro 2008, lançando o Pacote Energia-Clima. Observa-se que o início desta nova ênfase coincidiu com o primeiro mandato do José Manuel Barroso como presidente da Comissão Europeia, e seria, inclusive, a principal marca da sua gestão.

Como explicar a força que o tema ganhou? Piebalgs (2009) identifica o tema da mudança climática como principal driver. Já Ahtonen (2011) destaca as disputas relacionadas ao trânsito de gás da Rússia 
pela Ucrânia, que começaram em 2005 e teriam funcionado como catalisadores para que a UE avançasse. Os problemas na Ucrânia mostraram os riscos da falta de integração dos mercados e a necessidade de diversificação. Adelle et al. (2012, p. 32) lembram alguns outros acontecimentos que criaram um ambiente propício para que o tema se tornasse prioridade para a Comissão e carro-chefe da visão para o futuro da UE. Em primeiro lugar, a surpreendente rejeição da proposta para uma Constituição Europeia em 2005. Surpreendente para a Comissão em Bruxelas, que vinha atuando em um clima de euforia e avanços do multilateralismo europeu como exemplo para o mundo. Assim, os autores sugerem que "o tema das mudanças climáticas demonstrou-se útil como narrativa para convencer a opinião pública da necessidade de continuar com o processo de integração europeia". Ao mesmo tempo, foi justamente nesse período que os preços de petróleo começaram a subir fortemente, pressionando as contas externas da UE pela sua crescente dependência. Todos os documentos da Comissão colocam a questão da mudança climática junto com a da segurança energética. Observamos que a agenda de desenvolvimento sustentável se afunilou para a questão climática, diretamente ligada à matriz energética.

\subsubsection{0 pacote 20/20/20 em 2020}

Ainda sem preocupações com a crise financeira e econômica, a Comissão resolveu lançar um conjunto de medidas de forma integrada e com forte apelo comunicacional: normas de $20 \%$ a serem atingidas em 2020 como passo intermediário para 2050, quando a transição para uma economia de baixo carbono deveria ser completada (EUROPEAN COMMISSION, 2012b).

Em primeiro lugar, a redução de $20 \%$ de emissões de GEE, com relação ao nível de 1990, nos setores não cobertos pelo regime de comércio de licenças de emissão (prédios, agricultura, resíduos e transporte com exceção de aviação), o que representa cerca de $60 \%$ do total de 
emissões, com a obrigação de prestar contas anualmente à Comissão a respeito da implementação das metas. Curiosamente, a UE estabeleceu que, nesse caso, a meta de $20 \%$ poderia subir para $30 \%$ caso houvesse um acordo global.

Em segundo lugar, a diretiva com a norma vinculante para aumentar em $20 \%$ a participação de energias renováveis ${ }^{4}$ com relação ao nível de utilização em $2005^{5}$ e $10 \%$ no caso do setor de transporte. ${ }^{6}$ Pelas regras da União Europeia, independentemente das normas da Organização Mundial de Comércio (OMC), os Estados-membros estão proibidos de subsidiar atividades econômicas. A exceção histórica era a Política Agrícola Comum (PAC), com a justificativa de defender a segurança alimentar. Para as energias renováveis, a diretiva permite uma mesma exceção com a seguinte argumentação:

É necessário apoio público para se alcançarem os objetivos no que se refere à expansão da eletricidade produzida a partir de fontes renováveis, nomeadamente enquanto os preços da eletricidade no mercado interno não refletirem todos os custos e benefícios ambientais e sociais das fontes de energia utilizadas. ${ }^{?}$

Os chamados "regimes de apoio" podem implicar "a ajuda aos investimentos, as isenções ou reduções fiscais e o reembolso de impostos".

Em terceiro lugar, a meta de $20 \%$ de aumento da eficiência energética com base em projetos a partir de 2005 até 2020. Esta meta não foi, em um primeiro momento, acompanhada de normas vinculantes (ver adiante).

Foi introduzida ainda uma diretiva para criar um marco legal para o desenvolvimento da tecnologia para captura e armazenamento (Carbon Capture and Storage (CCS)) de $\mathrm{CO}_{2}{ }^{8}$ Neste caso, até 2013 não 
havia nenhuma experiência economicamente viável de CCS no mundo, e o objetivo da Comissão é alcançar isso em 2020.

Ainda fazia parte do pacote uma reforma do regime de comércio de licenças de emissões para torná-lo mais abrangente e mais efetivo. ${ }^{9}$ Com isso, foi lançada a segunda fase do ETS (2008-2012), com participação de três países não membros: Noruega, Liechtenstein e Islândia. Além do $\mathrm{CO}_{2}$, entrou ainda a emissão de óxido nitroso. A penalidade pela emissão sem certificado subiu de 40 euros por tonelada para 100 euros por tonelada. Foi permitido o uso de certificados obtidos no Mecanismo de Desenvolvimento Limpo (CDM) do Protocolo de Kyoto, com o qual o esquema europeu integrou esforços em países em desenvolvimento como o Brasil. Com isso, de acordo com a própria UE, o ETS tornou-se a principal fonte de investimentos em energia limpa em países em desenvolvimento e economias em transição. ${ }^{10}$

O mercado de carbono aumentou seu volume de 7,9 bilhões de dólares em 2005 para 49,1 bilhões de dólares em 2007 e 147,9 bilhões de dólares em 2011.

Fica evidente o caráter mobilizador e publicitário das metas. Não há, evidentemente, fórmula científica que justifique que todas as metas sejam convertidas para 20\%, patamar a ser alcançado em 2020.

Para apoiar o 20/20/20, a Comissão apresentou, em novembro 2007, o Plano para Tecnologia de Energia Estratégia (Strategic Energy Plan (SET)), aprovado pelo Conselho em março de 2008. O objetivo do plano é estimular projetos inovadores nas várias áreas de tecnologias industriais de baixo carbono. A Comissão estimou, em 2009, ser necessário aumentar o investimento na UE dos 3 bilhões de euros para 8 bilhões por ano no período 2010-2020 para implementar efetivamente as ações do Plano SET. Ou seja, um investimento adicional de 50 bilhões de euros no período (EUROPEAN COMISSION, 2009 , p. 10). Este montante deveria ser um misto de recursos nacio- 
nais, europeus, público-privados, com o Banco Europeu de Investimento tendo um papel crucial na garantia de crédito por meio de fundos específicos.

A necessidade de fazer as normas serem acompanhadas de estímulos financeiros aumentou ainda mais diante dos graves problemas com as finanças públicas provocados pela crise a partir do final de 2008. Contudo, é preciso deixar claro que os financiamentos e subsídios europeus são instrumentos para convencer e influenciar as autoridades nacionais e locais e não garantem o investimento em si (KELLNER, 2012).

Conforme mencionado, as metas para 2020 são apresentadas como intermediárias, rumo à meta para 2050: cortar a emissão de GEE com relação ao nível de 1990 em $80 \%$ a 95\%, com dois terços de fontes de energia renováveis e geração de eletricidade praticamente sem emissões de GEE (EUROPEAN COMMISSION, 2012b).

A formulação e discussão em torno do Pacote Energia-Clima foram claramente lideradas pela Comissão e representaram a política mais importante da primeira gestão de Barroso, apoiado pelo governo alemão. Até 2009, a Comissão mobilizou suas competências nas áreas econômicas (mercado interno) e ambientais para legislar na área de energia (BUCHAN, 2009). A formalização da competência para a Comissão veio depois que ela de fato já estava atuando, por meio do Tratado de Lisboa (dezembro de 2009), que estipulou, pela primeira vez, uma competência formal e explícita para legislar e atuar na área de energia. O artigo 176 do Tratado de Funcionamento da União Europeia determina:

No âmbito do estabelecimento ou do funcionamento do mercado interno e tendo em conta a exigência de preservação e melhoria do ambiente, a política da União no domínio da energia tem por objetivos, num espírito de solidariedade entre os Estados-membros: 
Giorgio Romano

a) assegurar o funcionamento do mercado da energia;

b) garantir a segurança do aprovisionamento energético da União;

c) promover a eficiência energética e as economias de energia, bem como o desenvolvimento de energias novas e renováveis; e

d) promover a interconexão das redes de energia.

Mas, ao mesmo tempo, o dispositivo legal explicita que não se trata ainda de constituir uma nova política comunitária e deixa para os Estados-membros a competência para "determinarem as condições de exploração dos seus recursos energéticos, a sua escolha entre diferentes fontes energéticas e a estrutura".

\section{Avaliação dos Resultados}

Entre 1995 e 2010, houve um aumento do consumo total em energia final de $8 \%$. Este consumo de energia parou de crescer por volta de 2005/2006, estabelecendo-se em torno de 1825 Mtoe, para diminuir depois, em grande parte sob o impacto da crise, para 1800 Mtoe em 2008. Os dados do consumo de energia final per capita mostram um crescimento de $6 \%$ em 2005 com relação a 1995, caindo para 1\% em 2010, sempre em comparação com 1995 (EUROPEAN COMMISSION, 2012a). De qualquer forma, a intensidade energética - a relação entre o consumo de energia e o PIB - diminuiu entre 2003 e 2009 em 10\% (EUROPEAN COMMISSION, 2010b) e houve uma queda na emissão de GEE de 10\% em 2009 com relação aos níveis de 1995 (EUROPEAN COMMISSION, 2012a). Nas Tabelas 1, 2 e 3, pode-se observar um constante aumento da participação da energia renovável no consumo final, na geração de eletricidade e no transporte. 
Segurança Energética e Mudanças Climáticas na União Europeia

Tabela 1

Participação de energia renovável no consumo total

\begin{tabular}{lcccccc} 
& $\mathbf{2 0 0 1}$ & $\mathbf{2 0 0 6}$ & $\mathbf{2 0 0 9}$ & $\mathbf{2 0 1 0}$ & Meta 2010 & Meta 2020 \\
\hline Eletricidade & $13,4 \%$ & $15,3 \%$ & $19,1 \%$ & nd & $21 \%$ & sem meta \\
Transporte & $0,3 \%$ & $2,1 \%$ & $4,2 \%$ & $4,7 \%$ & $5,75 \%$ & $10 \%$ \\
Calefação & $9,1 \%$ & $10,5 \%$ & $13,4 \%$ & nd & sem meta & sem meta \\
Total & $7,6 \%$ & $9,8 \%$ & $11,7 \%$ & $12,5 \%$ & sem meta & $20 \%$ \\
\hline
\end{tabular}

Fonte: European Commission (2010b; 2012a). Elaboração própria.

Tabela 2

Evolução das fontes para geração de eletricidade na UE

\begin{tabular}{lccccc}
\hline & $\begin{array}{c}\text { Combustíveis } \\
\text { sólidos }\end{array}$ & $\begin{array}{c}\text { Petróleo e } \\
\text { derivados }\end{array}$ & Gás & Nuclear & Renováveis \\
\hline 1995 & $39,4 \%$ & $8,6 \%$ & $8,6 \%$ & $30,7 \%$ & $12,5 \%$ \\
2005 & $29,2 \%$ & $4,2 \%$ & $20,9 \%$ & $30,1 \%$ & $14,7 \%$ \\
2010 & $24,7 \%$ & $2,6 \%$ & $23,6 \%$ & $27,4 \%$ & $20,9 \%$ \\
\hline
\end{tabular}

Fonte: European Commission (2012a, p. 85). Elaboração própria.

Tabela 3

Evolução da participação de bioenergia em transporte

\begin{tabular}{lcc}
\hline & Biocombustíveis & Biodiesel \\
\hline 2000 & $0 \%$ & $0,3 \%$ \\
2005 & $0,5 \%$ & $0,7 \%$ \\
2010 & $2,9 \%$ & $4,9 \%$ \\
\hline
\end{tabular}

Fonte: European Commission (2012a, p. 96). Elaboração própria.

O Gráfico 1, a seguir, confirma o avanço na produção de renováveis em detrimento das energias fósseis originárias de carvão e petróleo, embora nesse caso seja importante lembrar que são fontes cujas reservas estão se esgotando na Europa. De qualquer forma, entre 1995 e 2010, a participação do consumo do carvão diminuiu de $22 \%$ para $16 \%$, e, no caso de petróleo, houve uma queda de $39 \%$ para $35 \%$ (EUROPEAN COMMISSION, 2012a).

Sem dúvida, esses avanços são reflexos do ativismo legislativo da Comissão. As metas com relação à participação dos renováveis e da 
Giorgio Romano

\section{Gráfico 1}

Evolução da produção de energia por fonte na UE

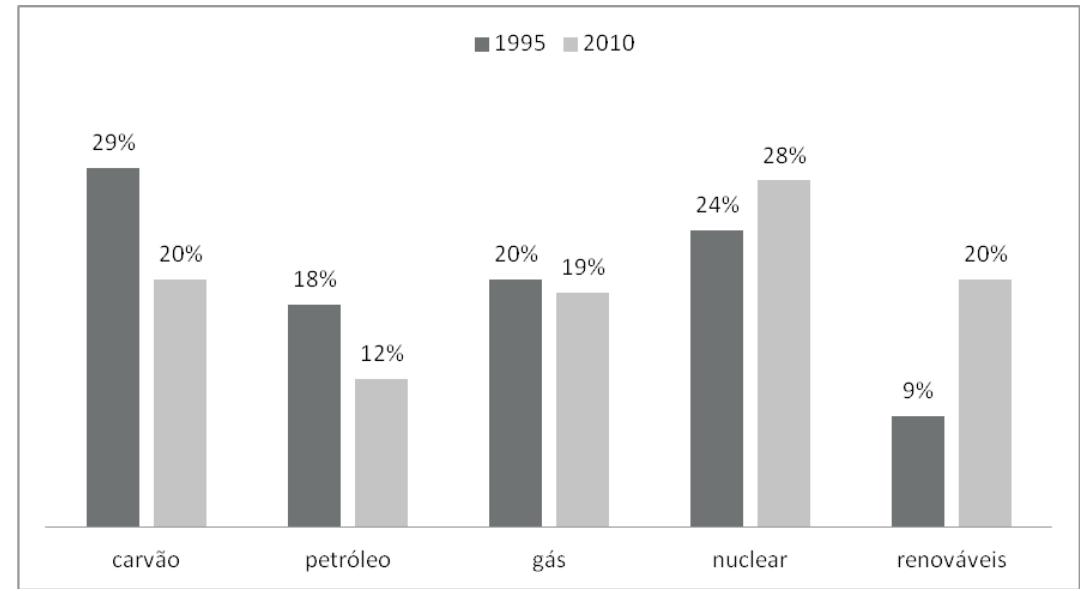

Fonte: European Commission (2012a, p.16). Elaboração própria.

Obs.: Entre 1995 e 2010, houve uma queda de 13\% na produção de energia.

redução de emissões de GEE devem ser alcançadas, embora com o apoio da recessão econômica. No caso da meta para a eficiência, a própria Comissão estima que deverá ficar em 17\%, conforme já mencionado.

\subsection{Limites}

Não obstante o exposto anteriormente, há questionamentos com relação à capacidade da UE para avançar além de 2020. Um problema para a implementação das medidas são os grandes investimentos exigidos das empresas para provocar constante redução de GEE. Não está tão claro, como aparece nos documentos da Comissão, como isso se traduz em aumento da produtividade. Pelo menos no curto prazo, há aumento dos custos e risco de carbon leakage. ${ }^{11}$ De acordo com Annika Ahtonen (2011), analista do European Policy Centre (EPC), a regulação estimularia a migração de investimentos para outras áreas e identificaria um hiato entre o nível de decisão política em Bruxelas e a dinâmica do mercado, gerando o que ela denomina de 
Brussels bubble: regulação sem implementação. Pior ainda, por se tratarem de áreas que não são de competência europeia. O caso das metas para aumentar a eficiência energética dos prédios seria o maior exemplo. Haveria, de um lado, o ativismo da Comissão Europeia em elaborar políticas energéticas para as próximas décadas, mas, por outro lado, por enquanto não existe um mercado único para energia; não há coordenação política; e prevalece o interesse nacional, com os países-membros resistindo em transferir competência nessa área para o nível europeu. ${ }^{12}$

Uma mesma avaliação no que diz respeito ao hiato entre metas e resultados foi levantada pela assessoria econômica do European Trade Union Institute (ETUI), enfatizando a falta de geração de empregos, sempre anunciada nas medidas. $\mathrm{O}$ pacote de estímulo à economia na Alemanha, em 2009, que trocava carros velhos por novos, tinha claramente um componente ambiental, mas não havia nenhuma obrigação de conteúdo local, e empresas como a Hyundai se aproveitaram disso por meio de importações. ${ }^{13}$

\subsection{Dependência energética}

Conforme comentado anteriormente, a política energética dialoga, de um lado, com a questão ambiental, em particular a questão climática, e, de outro lado, com a segurança de fornecimento e dependência externa. As políticas energéticas pretendem, portanto, agir nas duas frentes com um discurso de convergência e sinergia, embora isso nem sempre seja automático.

A segurança energética, inclusive, tornou-se um problema de contas externas e representou, em 2011, um gasto com importações do bloco em seu conjunto de 388 bilhões de euros. ${ }^{14} \mathrm{O}$ Gráfico 2 mostra a evolução da dependência de importação das principais fontes de energia com relação ao consumo interno total. Deve-se considerar 


\section{Giorgio Romano}

\section{Gráfico 2}

Evolução da dependência de importação de energia da UE em $\%$ do consumo total

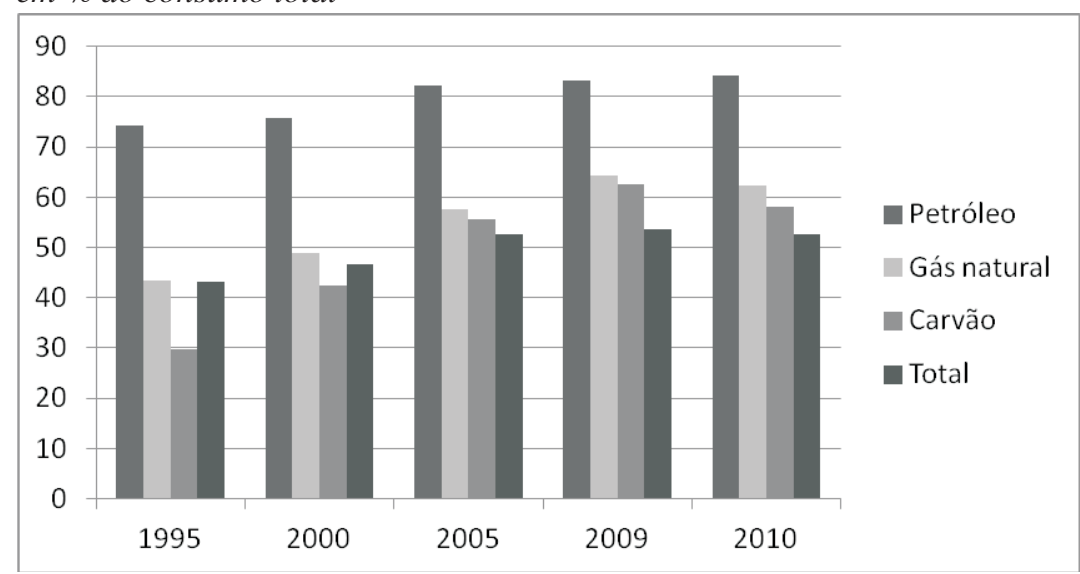

Fonte: European Commission (2012a). Elaboração própria

aqui o esgotamento das fontes fósseis na UE, o que faria essa conta aumentar, se mantidas as demais variáveis.

O Gráfico 3 mostra de forma surpreendente que a fonte que mais teve as suas importações aumentadas é justamente a que mais emite GEE em seu uso: o carvão. Isso se explica, de um lado, pelo esgotamento e abandono da produção nacional, com exceção da Polônia, Espanha e Alemanha, sendo que nesses últimos dois casos a questão é social, enquanto para a Polônia o carvão se tornou símbolo da sua independência diante da Rússia. O carvão, de fato, tem muito mais países produtores/exportadores, o que significa que o seu uso aumenta a segurança energética, diminuindo a dependência de um ou poucos países específicos. Outro fator é a disponibilidade no mercado internacional do carvão dos Estados Unidos a preços competitivos, uma vez que internamente está sendo substituído pelo gás de xisto.

Supondo que a UE seja vitoriosa em alcançar suas metas e chegar a $20 \%$ de energias renováveis em 2020 e 30\% em 2030, ainda se coloca a questão de onde virão os outros $70 \%$. O Gráfico 4 mostra a partici- 
Segurança Energética e Mudanças Climáticas na União Europeia

\section{Gráfico 3}

Evolução da importação por fonte com relação a 1995

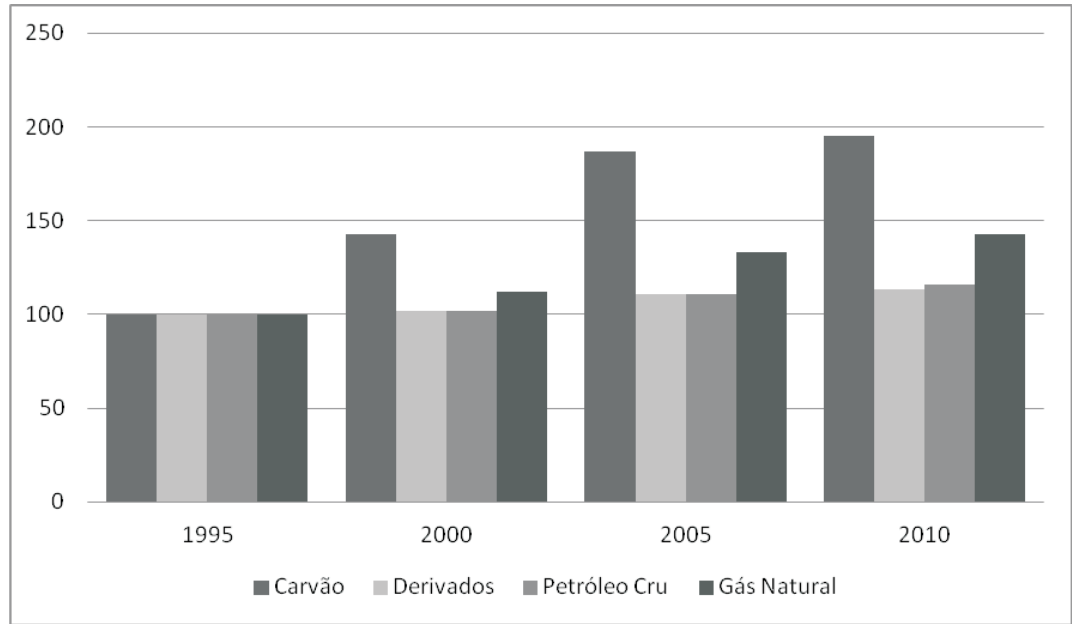

Fonte: European Commission (2012a). Elaboração própria.

\section{Gráfico 4}

Origem da importação de petróleo e gás pela UE em 2010

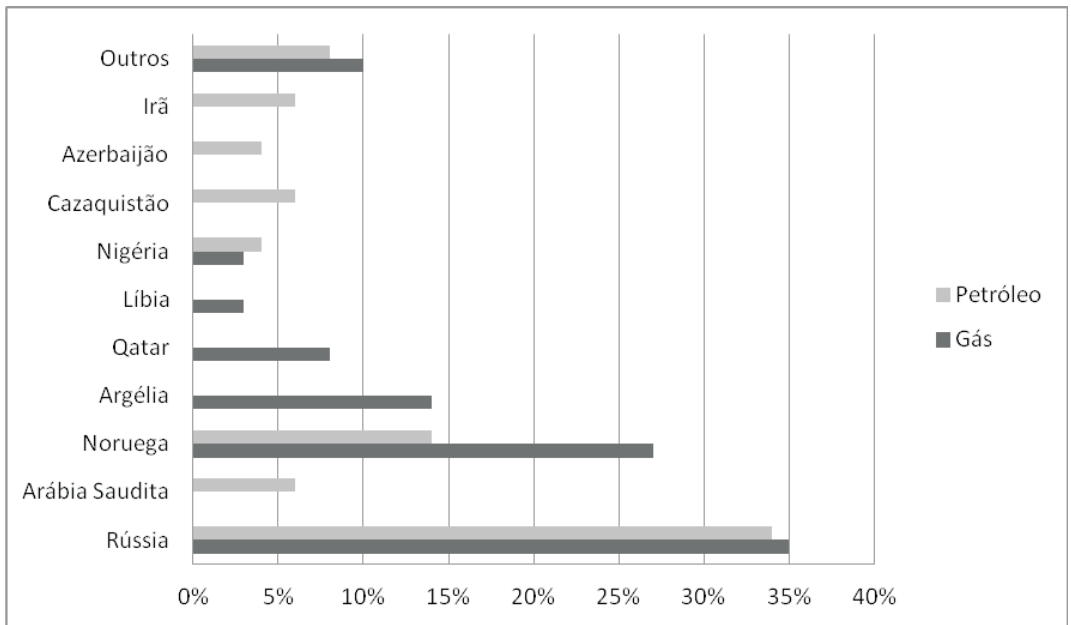

Fonte: European Commission (2012a). Elaboração própria. 
pação dos vários players, com notório destaque para a Rússia. Observa-se ainda o avanço da participação do Qatar, que foi objeto de grandes investimentos para permitir exportação de gás natural liquefeito (GNL) para os Estados Unidos. Com o avanço do gás de xisto nos Estados Unidos, esta produção está se dirigindo para o mercado europeu em detrimento da importação da Rússia. Enquanto o volume importado da Rússia vem caindo desde 2008, de 5,1 milhões de Terajoule (TJ) ${ }^{15}$ para menos de 4,4 milhões de TJ em 2010, a importação do Qatar pulou de 0,2 milhão de TJ para 1,2 milhão de TJ no mesmo período (EUROPEAN COMMISSION, 2012a, p. 63).

A Tabela 4 mostra que, embora toda a atenção sempre esteja voltada à questão do gás da Rússia, o que se justifica de fato pelo volume expressivo, houve crescimento significativo da importação do carvão a partir do início dos anos 2000, como também do petróleo.

\section{Tabela 4}

Evolução da importação da Rússia pela $U E$

\begin{tabular}{lcccc}
\hline & $\mathbf{1 9 9 5}$ & $\mathbf{2 0 0 0}$ & $\mathbf{2 0 0 5}$ & $\mathbf{2 0 1 0}$ \\
\hline Carvão (em 1.000t) & 8.794 & 14.957 & 48.452 & 47.804 \\
Petróleo e NGL (em 1.000t) & 76.319 & 118.229 & 188.079 & 180.654 \\
Gás natural (em TJ) & 4.234 .713 & 4.539 .709 & 5.099 .721 & 4.384 .008 \\
\hline
\end{tabular}

Fonte: European Commission (2012a, p. 61-63). Elaboração própria.

\subsubsection{Perspectivas para a retomada da produção de energias fósseis na UE}

Na UE, o principal país produtor de petróleo é o Reino Unido, mas mesmo este teve seu pico entre 1999 e 2001 e, depois, tornou-se importador líquido. A Dinamarca, com produção offshore, continua sendo um exportador líquido, mas em volumes pequenos, enquanto a Romênia é o único país com alguma expectativa de aumentar sua produção offshore no Mar Negro. 
No caso do gás convencional, há produção no Reino Unido, nos Países Baixos, na Alemanha, na Polônia, na Romênia e em Chipre, que no seu conjunto conseguem cobrir $35 \%$ da demanda. Com exceção da Romênia e de Chipre, a tendência é a diminuição da capacidade de produção. A Noruega cobriu, em 2010, $15 \%$ da demanda. Há esperanças de que a Noruega possa compensar o esgotamento de suas reservas com novas descobertas no Oceano Ártico. Embora a Noruega não seja membro da UE, ela faz parte da Associação Europeia de Livre Comércio, que, por sua vez, criou, junto com a UE, o Espaço Econômico Europeu (EEE). Além disso, a Noruega mantém sua moeda atrelada ao euro.

A partir do sucesso do gás de xisto nos Estados Unidos, o tema entrou em debate na UE. Até 2013, não havia produção de gás de xisto na Europa. Há interesse por parte da Polônia e do Reino Unido, enquanto em outros países prevalece a cautela com relação aos impactos ambientais. Estima-se que há reservas significativas recuperáveis também na Áustria e na Hungria. Há uma forte influência do sucesso nos Estados Unidos e grandes expectativas de que o Reino Unido possa copiá-lo. Mas estudos do British Geological Survey, instituto público para a pesquisa geológica, sugerem cautela e enfatizam a grande diferença geológica entre as áreas com reservas de gás de xisto nos Estados Unidos e no Reino Unido. ${ }^{16}$

\subsubsection{Energia nuclear}

Para vários países da UE, com destaque para a França, ${ }^{17}$ a energia nuclear era vista como garantia de segurança energética. A UE tornou-se a região com maior número de usinas nucleares em operação: 150 (2010). Estas são responsáveis por um terço da eletricidade total e dois terços da eletricidade de baixo carbono. Na realidade, houve uma participação bastante estável entre 1990 (30\%) e 2005 (30,1\%). Depois, começou uma queda relativamente pequena, chegando a 27,4\% em 2010 (EUROPEAN COMMISSION, 2012a), devido 
principalmente à evolução na Alemanha, onde caiu de 28,5\%, em 1995, para 22,4\%, em 2010 (EUROPEAN COMMISSION, 2012a). Até o desastre na usina atômica no Japão, em 2011, havia um movimento de ressurgimento da energia nuclear. Ela estaria bem posicionada para contribuir com o combate às mudanças climáticas e diminuir a dependência energética (há muitas opções para o fornecimento do urânio), e era considerada uma das fontes mais baratas de energia de baixo carbono (EUROPEAN COMMISSION, 2010b).

Depois do desastre em Fukushima, no Japão, em março de 2011, o governo da Alemanha tomou a decisão de excluir a energia nuclear até 2021/2022. ${ }^{18}$ Tratou-se de uma decisão unilateral sem nenhuma consulta à UE, tomada diante da comoção da opinião pública. Outros países que tendem a seguir o exemplo da Alemanha são a Bélgica (com duas usinas) e a Áustria. A Finlândia, por outro lado, que já dispunha de quatro usinas nucleares em operação, continuou firme na construção de uma nova planta para entrar em operação em 2015.

\section{Política Energética Internacional}

A política da UE no campo externo reflete as opções internas e se divide em, de um lado, garantir o suprimento e, de outro, promover o uso sustentável de energia em âmbito global, apresentando a experiência europeia recente como exemplo a seguir. Em ambos os casos, isso exige um ação coordenada e, se possível, comunitária. Houve uma clara estratégia por parte da Comissão de incluir o tema da energia nas relações internacionais por meio de diálogos com os principais players, como no caso da Rússia (ver a seguir). Ademais, houve um esforço para coordenar as posições no âmbito da Agência Internacional de Energia (AIE) e de outros fóruns em que o tema aparece, tais como no G7 e no G20. Outros exemplos de articulações internacionais da UE em torno desse tema são: o International Partnership on Energy Efficiency Cooperation (Ipeec), criado em 2008, que en- 
volve os países do G8, além de China, Índia e Coreia do Sul; o International Renewable Energy Agency (Irene); e a Carta de Energia de 1994, que estabelece garantias para investimentos em energia nos países signatários, em particular nos países da Europa Central e Oriental no intuito de desenvolver o potencial energético nestes países e garantir a segurança de abastecimento de energia da UE.

\subsection{Rússia}

A dependência do fornecimento da Rússia divide as opiniões na União Europeia, com forte preocupação entre os dez países que pertenciam ao bloco soviético. A Alemanha costuma enfatizar a interdependência: o fato de a Rússia depender da UE como mercado exportador diminuiria sua capacidade de usar sua posição no mercado como instrumento de poder político.

Oitenta por cento do gás exportado pela Gazprom para a Europa é por meio dos gasodutos que passam pela Ucrânia. Uma série de disputas comerciais entre a Gazprom e a empresa estatal da Ucrânia, Naftogaz, começou em 2005 e adquiriu um caráter geopolítico. Em janeiro de 2009, chegou a provocar uma interrupção do fornecimento para países europeus. A Bulgária, em particular, ficou sem gás. A crise de suprimento de gás de 2009 demonstrou a necessidade de nova regulação com planos de contingência e maiores canais de comunicação. Assim, a Comissão Europeia publicou, em outubro de 2010, a Regulação 994 "relativa a medidas destinadas a garantir a segurança do aprovisionamento de gás". Foi adotado como critério de segurança de fornecimento o N-1, no qual $\mathrm{N}$ é a demanda regular do gás e 1 é o volume importado do fornecedor principal. Ou seja, um plano de contingência que prevê o suprimento por um tempo na ausência de importações do fornecedor principal. A integração do mercado de gás deve diminuir o poder de barganha da Rússia, permitindo assim o abastecimento via outros países e o uso de GNL, pelo menos no curto prazo. 
Podem-se identificar três outras mudanças que tornam o reaparecimento da crise em torno do trânsito pela Ucrânia menos provável. Em primeiro lugar, os acontecimentos representaram também uma perda da credibilidade na Rússia como fornecedor confiável, que era alta, considerando que, mesmo durante toda a Guerra Fria, nunca houve interrupção dos fornecimentos. Assim, a Rússia tem interesse em evitar novas crises. Em segundo lugar, houve o impacto das mudanças globais no mercado de gás com a produção do gás de xisto nos Estados Unidos. Isso liberou, como já mencionado, o potencial de GNL para exportação do Qatar que estava previsto para os Estados Unidos. Em terceiro lugar, houve a novidade da entrada em vigor do Nord Stream, projeto geopolítico viabilizado por meio da parceria entre o ex-primeiro-ministro da Alemanha, Gerhard Schröder, e o presidente da Rússia, Vladimir Putin. Essa rede liga a Rússia diretamente à Alemanha, passando pelo Mar Báltico. ${ }^{19}$ Trata-se de um megaprojeto de 1.224 quilômetros de gasoduto offshore, passando pelas Zonas Econômicas Exclusivas da Rússia, Finlândia, Suécia, Dinamarca e Alemanha. O consórcio Nord Stream é composto pela Gazprom (51\%), duas empresas de gás da Alemanha (a subsidiária da Basf, Wintershall, e a E.ON Ruhrgas), cada uma com 15,5\%, e ainda a holandesa Gasunie e a Francesa GDF Suez, cada uma com 9\%. A inauguração oficial ocorreu em novembro de 2011, e o gás começou a fluir em 2012. ${ }^{20}$

\section{Impacto da Crise Global}

A crise financeira e econômica se contrapôs de várias formas ao avanço da política energética da UE. Podem-se fazer alguns paralelos com a situação monetária no que diz respeito à fraqueza institucional incapaz de dar respostas comunitárias à altura dos desafios, o que por sua vez reforça tendências centrífugas. De fato, como no caso do euro, o dilema é avançar ou recuar. A narrativa da Comissão Europeia para manter a sua política tentou mostrar como as políticas ener- 
géticas e do clima podem contribuir com a redução dos custos e com a competitividade da indústria e tecnologia europeias. Ou seja, seria justamente a continuidade dessas políticas que contribuiria com a superação da crise econômica.

Os desafios são múltiplos. Em primeiro lugar, há a pressão sobre os orçamentos dos governos nacionais e locais no contexto dos crescentes déficits públicos e das políticas de austeridade. A mesma pressão acaba também gerando uma crise em torno do orçamento da própria Comissão Europeia para o período 2014-2020. ${ }^{21}$ Em segundo lugar, se no médio e longo prazos a narrativa da Comissão faz sentido, no curto prazo exige altos investimentos sem perspectiva de retorno imediato. Em um clima de incertezas e baixa propensão ao risco, os investimentos necessários acabam não se concretizando. Isso aumenta ainda mais o hiato entre as normas e as metas europeias e a sua implementação no território nacional e local, diminuindo sua credibilidade. Em terceiro lugar, em relação ao ponto anterior, a crise abre um espaço para uma oposição explícita às políticas da Comissão Europeia com o argumento de que estas encarecem o custo da produção na Europa e, portanto, complicariam ainda mais a recuperação das economias diante da concorrência da China e dos Estados Unidos, ambos com custos de energia muito inferiores. Em quarto lugar, talvez o mais grave, há uma queda brutal da confiança nas instituições da UE. A Europa é vista cada vez mais como parte do problema e não como parte da solução. O foco no curto prazo e o olhar mais voltado para a esfera nacional criaram um ambiente adverso para a Comissão Europeia manter o seu dinamismo nessa área. Em quinto lugar, um fenômeno específico que complica um dos pilares da política comunitária: os preços do carbono despencaram, ${ }^{22}$ paralisando o mercado em certificados e desarticulando um dos principais incentivos para a indústria investir em eficiência energética e reconversão rumo a uma economia de baixo carbono. Ao mesmo tempo, reduziu-se drasticamente a receita pública vinda dos leilões que eram fonte importante para o financiamento de ações climáticas. Em sexto lugar, surge uma ilusão de avanços na queda das emissões de GEE e do uso de energia 
provocada não por alteração da matriz ou da estrutura de produção, mas pela recessão. Isso gera a falsa impressão de que o problema estaria sob controle.

Um exemplo da oposição política que se fortalece com a crise é a publicação, em setembro de 2010, de um comunicado conjunto das entidades patronais e sindicais da indústria química da Alemanha, criticando o conceito da Energiewende, palavra alemã com a qual se expressa a revolução na matriz energética necessária para combater as mudanças climáticas. $\mathrm{O}$ argumento é de que as energias alternativas, em particular a eólica e a solar, não seriam confiáveis para o fornecimento à indústria e, sobretudo, de que essa política tornaria a indústria alemã menos competitiva. ${ }^{23}$

Em 2012, a Polônia vetou a adoção do Road Map 2050 no Conselho dos Ministros, e as decisões, uma vez levadas a este âmbito, devem ser por unanimidade, colocando na defensiva pela primeira vez, desde a década de 2000, a política da Comissão. A atuação do governo da Polônia, que contou com apoio de praticamente todos os deputados poloneses representados no Parlamento Europeu, deve-se ao fato de o país desconfiar que o Road Map 2050 pudesse ser utilizado para desmontar sua opção pelo carvão como principal fonte de energia. No ano seguinte, a situação complicou-se ainda mais pelo lado da Comissão, que viu sua proposta para salvar o ETS ser derrotada por uma margem pequena de votos no Parlamento Europeu. A proposta da Comissão era cortar a oferta de licenças em $15 \%$ para provocar um aumento do preço. $\mathrm{O}$ argumento contrário era de que a medida iria aumentar o custo da produção na Europa, diante da tendência de baixa dos custos de produção nos Estados Unidos devido à queda significativa do preço de energia para a indústria com o gás de xisto.

\section{Considerações Finais}

Embora seja inegável o avanço na esfera europeia, a política energética ainda é caracterizada por preocupações nacionais. Sem dúvida, a 
crise provocou uma descrença muito grande. A opinião pública perdeu a confiança, ficaram evidentes as limitações das instituições, o seu projeto parece bloqueado. Mas, por outro lado, existe uma profunda interdependência na União Europeia. Os países estão ligados a uma rede de relações institucionais e jurídicas, sociais e políticas cuja magnitude e complexidade só deve aumentar, exatamente devido às respostas, embora lentas e tardias à crise, com as quais as instituições comunitárias amplificam as suas competência e área de atuação. $\mathrm{O}$ dilema geral para a União Europeia projeta-se também na sua política energética: aprofundar ou recuar. Jos Delbeke, diretor-geral da DG Ação Climática, está convencido de que, na próxima rodada de alteração do Tratado de Funcionamento da União Europeia, a energia ganhará o status de política comunitária, o que refletiria a força da interdependência e dos ganhos a serem alcançados com ações comunitárias. $^{24}$

Assim, apesar dos problemas conjunturais e estruturais que apontam para uma inevitável diminuição do peso econômico e político da União Europeia, ela continua a ser um ator estratégico, em particular para o debate sobre os parâmetros para o desenvolvimento sustentável.

\section{Notas}

1. Este trabalho foi possibilitado por meio de uma bolsa de estudo da Fundação Friedrich Ebert (FES), que deu suporte logístico para realizar a pesquisa em Bruxelas durante o mês de setembro de 2012. Foram entrevistados especialistas no assunto dos seguintes centros de pesquisa: Centre for European Policy Studies, Climate Action Network Europe (CAN), Vision on Tecnology (VITO), European Policy Center e do European Trade Union Institute (ETUI); formuladores de política das Direções-Gerais (DG): Energia, Ação Climática e Desenvolvimento \& Cooperação; a missão brasileira perante a UE; e membros do Parlamento Europeu atuando na temática. 
Giorgio Romano

2. O instrumento jurídico mais utilizado pela Comissão para atuar nessa área é a diretiva, que deve ser traduzida em legislação nacional a ser submetida à aprovação pela Comissão, o que permite, dentro dos parâmetros estabelecidos, levar em conta as especificidades nacionais. Outro instrumento legal à disposição da Comissão é o regulamento, que estabelece normas de aplicação direta no sistema jurídico. As diretivas são resultado de um processo de negociação entre a Comissão, que detém poder de iniciativa; o Parlamento, que pode propor emendas; e o Conselho (intergovernamental), que decide. Esse processo dura em média um ano. Estados-membros devem reportar-se à Comissão sobre o andamento da implementação da diretiva. O Parlamento conquistou o direito de avaliar os relatórios de progresso. A cada dois anos, a Comissão publica uma compilação.

3. Atualmente codificado como art. 11 do Tratado sobre o Funcionamento da União Europeia, 2009.

4. São consideradas energias renováveis: eólica, solar, aerotérmica, geotérmica, hidrotérmica e oceânica, hidráulica, de biomassa, de gases dos aterros, de gases das instalações de tratamento de águas residuais e biogases. Mais especificamente, a Comissão diferencia entre renováveis de primeira geração (hidro, onshore eólica, biomassa/biocombustíveis de primeira geração) e de segunda geração (eólica offshore, solar, carros elétricos, segunda geração de biocombustíveis e biomassa avançada).

5. A escolha de 2005 como ano base deve-se ao fato de ser considerado o primeiro ano a respeito do qual se dispõe de dados confiáveis sobre as cotas nacionais de energia provenientes de fontes renováveis.

6. Diretiva 2009/28/CE (COMISSÃO EUROPEIA, 2009).

7. Ponto 27 do preâmbulo da Diretiva 2009/28/CE (COMISSÃO EUROPEIA, 2009).

8. Diretiva 2009/31/EC (DIRECTIVE..., 2009a).

9. Emission Trading Scheme Directive 2009/29/EC (DIRECTIVE..., 2009b).

10. Disponível em: <http://ec.europa.eu/clima/policies/ets/reform/index en.htm>.

11. Carbon leakage é definido pela UE como sendo "a situação que pode surgir quando, por motivos relacionados a gastos com políticas de redução de GEE, as empresas transferem produção para outros países com regras e normas menos rígidas. Isso pode gerar aumento no total das suas emissões no âmbito global. O risco de carbono leakage é maior em indústrias intensivas em energia. 


\section{Segurança Energética e Mudanças Climáticas na União Europeia}

Disponível em: <http://ec.europa.eu/clima/policies/ets/cap/leakage/index_ en.htm>.

12. Entrevista concedida em 7 de setembro de 2012, em Bruxelas. Ver também Ahtonen (2011).

13. Entrevista concedida por Bela Galboczi em 10 de setembro de 2012 em Bruxelas.

14. Disponível em: <http://ec.europa.eu/europe2020/pdf/themes/13 energy_and_ghg.pdf $>$.

15. $1 \mathrm{TJ} \sim 278 \mathrm{MWh}$.

16. Disponível em: <http://nora.nerc.ac.uk/13090/1/shale_gas_prosp_final_ edit2.pdf $>$ e <http://www.bgs.ac.uk/research/energy/shaleGas/howMuch.html>.

17. Na França, a energia nucelar alcançou em 2010 uma participação de $75 \%$ na sua geração de eletricidade (EUROPEAN COMMISSION, 2012a), uma opção geopolítica que tradicionalmente contou com amplo apoio no espectro político interno.

18. Na verdade, a Alemanha voltou à proposta do governo da coalizão partido verde e partido social-democrata, que havia sido revertida por Angela Merkel ao assumir o governo. Estão em jogo dezessete usinas que devem ser fechadas até o final de 2021, com possibilidade de extensão do prazo por um ano.

19. $O$ tratado definitivo foi ratificado pouco antes de Schroeder terminar seu segundo mandato, em 2005. Em seguida, ele se tornou CEO da North Stream. De qualquer forma, sua sucessora, a primeira-ministra Angela Merkel, deu continuidade a essa política.

20. Disponível em: <http://www.nord-stream.com/about-us/>.

21. O Orçamento da União Europeia equivale a cerca de $1 \%$ do PIB. O Parlamento já indicou no passado seu desejo de aumentá-lo para 5\%, mas nas negociações sobre o orçamento plurianual 2014-2020, realizadas no final de 2012, houve, sob pressão do Reino Unido, pela primeira vez na história da UE, um corte no orçamento de 34,4 bilhões de euros (sobre o total de 1 trilhão de euros). Ver: <http://www.guardian.co.uk/world/2013/feb/08/european-union-budgetnight-talks $>$.

22. Os preços começaram a cair de forma constante de 30 euros por tonelada de GEE em 2008 para 3 euros por tonelada em abril de 2013. 


\title{
Giorgio Romano
}

23. Disponível em: <http://www.igbce.de/download/7622-15978/ 1/xvi-26-25-09-2012-energiewende-gestalten.pdf >.

24. Entrevista concedida em 5 de setembro de 2012 em Bruxelas.

\section{Referências Bibliográficas}

\begin{abstract}
ADELLE, Camilla; RUSSEL, Duncan; PALLEMAERTS, Marc. A Coordinated European Energy Policy? The Integration of EU Energy and Climate Change Policies. In: SANDOVAL, I. S.; MORATA, F. European Energy Policy. An Environmental Approach. Cheltenham: Edward Elgar Publishing, 2012.
\end{abstract}

AHTONEN, Annika. Europe's Quest for Energy Security: Tackling the International an External Challenges. Panorama, Konrad Adenauer Stiftung, Singapore, n. 1, 2011.

BUCHAN, David. Energy and Climate Change: Europe at the Crossroads. Oxford: Oxford University Press, 2009.

COMISSÃO EUROPEIA. Directiva 2009/28/CE do Parlamento Europeu e do Conselho de 23 de abril de 2009 relativa à promoção da utilização de energia proveniente de fontes renováveis que altera e subsequentemente revoga as Directivas 2001/77/CE e 2003/30/CE. Jornal Oficial da União Europeia, 5 jun. 2009.

DIRECTIVE 2009/31/EC of the European Parliament and of the Council of 23 April 2009 on the Geological Storage of Carbon Dioxide and amending Council Directive 85/337/EEC, European Parliament and Council Directives 2000/60/EC, 2001/80/EC, 2004/35/EC, 2006/12/EC, 2008/1/EC and Regulation (EC) No 1013/2006. Official Journal of the European Union, Bruxelas, 5 Jun. 2009a.

DIRECTIVE 2009/29/EC of the European Parliament and of the Council of 23 April 2009 Amending Directive 2003/87/EC so as to Improve and Extend the Greenhouse Gas Emission Allowance Trading Scheme of the Community. Official Journal of the European Union, Bruxelas, 5 Jun. 2009b. 
Segurança Energética e Mudanças Climáticas na União Europeia

EUROPEAN COMMISSION. Green Paper. Towards a European Strategy for the Security of Energy Supply. Bruxelas, 2001.

Investing in the Development of Low Carbon Technologies (SET-Plan), COM(2009)519. Bruxelas, 2009.

Energy 2020. A Strategy for Competitive, Sustainable and Secure Energy. Bruxelas, 2010a.

. State of Play in the EU Energy Policy. Comission Staff Working Document SEC (2010) 1346 Final. Bruxelas, nov. 2010b.

_. EU-Russia Energy Dialogue. The First Ten Years 2000-2010. Bruxelas, 2011.

. EU Energy Figures. Luxemburgo, 2012a.

_. Energy Roadmap 2050. Luxemburgo, 2012b.

EUROPEAN UNION. A Secure Europe in a Better World. Bruxelas: European Security Strategy, 2003.

KELLNER, Karl. Financing Investments. Directorate-General for Energy/Renewables Research and Innovation Energy Efficiency, Bruxelas, jun. 2012.

PIEBALGS, Andris. How the European Unions Is Preparing the Third Industrial Revolution with an Innovative Energy Policy. European University Institute Working Paper 2009/11, 2009.

SANDOVAL, Israel Solorio; MORATA, Francecs. European Energy Policy. An Environmental Approach. Cheltenham: Edward Elgar Publishing, 2012.

SILVA, Antônio Costa. A segurança energética da Europa. Nação e Defesa, n. 116, 2007.

\section{Resumo}

\section{Segurança Energética e Mudanças Climáticas na União Europeia}

O estudo da economia política da energia é cada vez mais relevante para as Relações Internacionais em função do aumento da interdependência energética e da sua interação com os demais aspectos da agenda internacional, em particular as mudanças climáticas. Este trabalho pretende analisar os 


\section{Giorgio Romano}

avanços e as dificuldades da política energética da União Europeia (UE). O objetivo é identificar os fatores que levaram a Comissão Europeia a articular, sobretudo a partir de 2005, um ativismo inédito na área de energia, apesar da inexistência de uma competência formal para o estabelecimento de uma política energética comum. Isso resultou em uma legislação europeia inovadora e ambiciosa, analisada e avaliada neste trabalho a partir de documentos oficiais, da literatura recente e de entrevistas qualitativas com cerca de vinte formuladores e analistas de política, realizadas em Bruxelas, em setembro de 2012. Ficou evidente que a discussão em torno da mudança climática alterou o olhar sobre a questão energética. $O$ fato de a UE como um todo ser crescentemente deficitária no campo energético aumentou a relevância da questão da segurança e acabou também estimulando a busca de fontes alternativas, ao mesmo tempo em que condicionou suas relações externas, em particular com a Rússia. Houve avanços importantes, sobretudo a partir do estabelecimento de normas rígidas e mandatórias para os países-membros com o Pacto Energia-Clima que justificavam o papel de liderança que a UE estava assumindo nas negociações internacionais sobre o clima. A busca de respostas comunitárias e de convergência entre os objetivos relacionados às mudanças climáticas, à segurança energética e à competividade econômica sofreu uma forte pressão com o impacto da crise global, depois de setembro de 2008. A crise evidenciou o ainda frágil arcabouço institucional que, diante do contexto de recessão, acabou reforçando tendências centrífugas em torno de interesses e estratégias nacionais. Ao mesmo tempo, complicou a realização dos investimentos necessários para avançar na implementação das políticas delineadas na área de energia e clima. De outro lado, existe uma inegável e forte interdependência entre as economias do bloco, e a Comissão Europeia insistiu em defender os ganhos a serem alcançados com ações comunitárias.

Palavras-chave: Política Energética - Mudanças Climáticas - União Europeia - Segurança Energética

\section{Abstract}

\section{Energy Security and Climate Change in the European Union}

The study of economic energy policy is more relevant to International Relations today because of the increase in energy interdependence and its interaction with other issues on the international agenda, climate change in particular. This paper will analyze the progress made and the obstacles that 


\section{Segurança Energética e Mudanças Climáticas na União Europeia}

lie ahead for energy policy in the European Union (EU). The objective is to identify the factors that have led the European Commission, especially after 2005, to unleash an remarkable degree of activism in the energy area, despite the lack of an official forum for the establishment of a common energy policy. This resulted in an innovative and ambitious European legislative program, which is examined in this paper and evaluated on the basis of official documents, the recent literature and qualitative interviews with around twenty policymakers and analysts, carried out in Brussels in September 2012. It was clear that the discussion of climate change changed the view of energy issues. The fact that the EU as a whole has a growing energy deficit increased the relevance of the issue of security and also stimulated the search for alternative sources, at the same time that it placed conditions on its external relations, especially with Russia. Important progress was made, in particular with regard to the establishment of strict mandatory standards for the countries that were members of the Energy-Climate Agreement, that justified the leadership role that the EU began to assume in international climate discussions. The search for community responses and convergence among the objectives related to climate change, energy security and economic competitive position suffered enormous pressure with the impact of the global crisis after September 2008. The crisis revealed an institutional framework that was still fragile and, in the context of a recession, ended up reinforcing centrifugal trends around national interests and strategies. At the same time, this made the realization of the investments necessary to move forward with the implementation of policies in the energy and climate area more complicated. On the other hand, there is an undeniable and strong interdependence among the economies in the block, and the European Commission has insisted on defending the gains that could be achieved with community actions.

Keywords: Energy Policy - Climate Change - European Union - Energy Security 